RESEARCH PAPER RP773

Part of Journal of Research of the National Bureau of Standards, Volume 14, March 1935

\title{
ELECTROLYTIC OXIDATION OF XYLOSE IN THE PRESENCE OF ALKALINE EARTH BROMIDES AND CARBONATES
}

\author{
By Horace S. Isbell and Harriet L. Frush
}

\section{ABSTRACT}

It has been found that calcium, strontium, and magnesium xylonates can be prepared by electrolytic oxidation in a manner analogous to that used for preparing calcium gluconate and can be separated as crystalline salts in good yield from the electrolyzed solutions. Crystalline calcium and magnesium xylonates are new substances which may prove useful intermediates for the preparation of other substances such as threose or trihydroxyglutaric acid.

\section{CONTENTS}

I. Introduction

II. Experimental details

1. Oxidation method

2. Preparation of calcium xylonate 361

3. Preparation of magnesium xylonate 361

4. Preparation of strontium xylonate

\section{IN'TRODUCTION}

In a previous publication ${ }^{1}$ a process was described for the oxidation of aldose sugars which consisted in passing an electric current through the solution containing the sugar, a bromide, and calcium carbonate. $^{2}$ The bromide by electrochemical decomposition yields bromine which reacts with the sugar, regenerating the bromide, so that a small quantity will facilitate the oxidation of a large amount of the sugar. By adding calcium carbonate and the sugar at a suitable rate, and separating the calcium gluconate as it crystallizes from the electrolyte, the process becomes continuous, ${ }^{3}$ thereby giving a very simple method for the preparation of calcium gluconate. Inasmuch as xylose is one of the more abundant sugars, several years ago the authors began the study of methods for oxidizing xylose and separating the resulting xylonic acid. Originally the application of the electrolytic process to xylose was limited by the fact that calcium xylonate was not known in the crystalline state and hence

\footnotetext{
${ }^{1}$ Isbell and Frush. BS J. Research 6, 1145 (1931) RP328.

2 One of us conceived this process early in 1928 and finally the procedure described in the reference cited in footnote 1 was evolved. In the meantime E. L. Helwig, of Röhm \& Haas Co., and R. Pasternack, of Chas. Pfizer \& Co., conceived similar processes and filed U. S. patent applications which were placed in interference with the application of Isbell. U. S. Patent No. 1937273 has now been issued to Helwig, and U.'S. Patent No. 1976731 has been issued to Isbell.

${ }^{3}$ Isbell, Frush, and Bates. BS J. Research 8, 571 (1932) RP436.
} 
it was necessary to separate the xylonic acid as a basic calcium xylonate. The use of the basic salt is disadvantageous because the strong alkali causes degradation of any unoxidized sugar, thereby reducing the efficiency for continuous operation. After many unsuccessful attempts to obtain crystalline calcium xylonate we applied the electrolytic oxidation method to xylose in the presence of strontium carbonate and prepared a considerable quantity of strontium xylonate. ${ }^{4}$ As strontium salts have limited application, the crystalline magnesium salt ${ }^{5}$ was prepared and found to be obtained readily by the electrolytic method. A solution containing the barium salt was also prepared, but all attempts at crystallization failed. While this work was in progress attempts were made to bring calcium xylonate to crystallization. Finally this was accomplished by one of us. ${ }^{6} \quad$ Since the new salt forms crystals which can be separated readily from the mother liquor, it is now possible to prepare pure crystalline calcium xylonate in any amount by the electrolytic process described in detail for the manufacture of calcium gluconate.

TABLe 1.-Electrolytic oxidation of xylose ${ }^{1}$

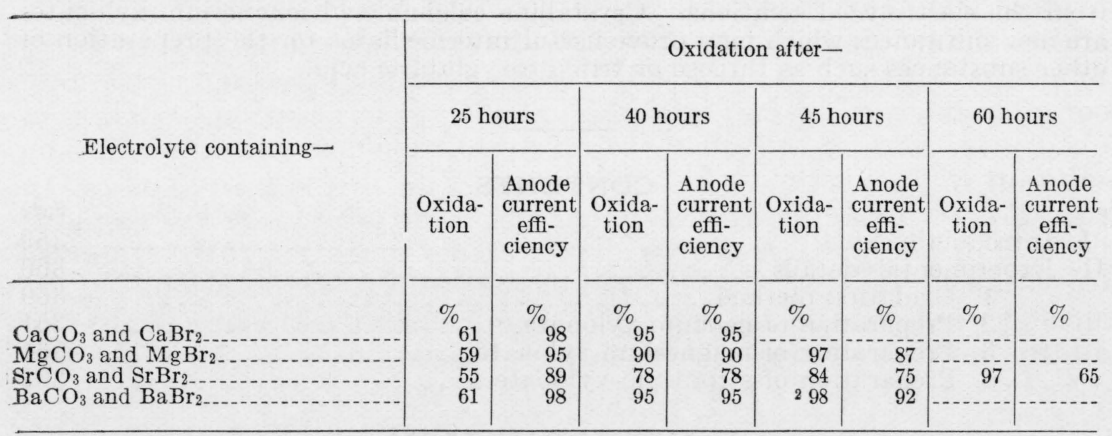

10.75 mole of xylose in $1,500 \mathrm{ml}$ of water saturated with $\mathrm{CO}_{2}$ and containing the substances given in the first column.

2 This sample was taken after 43 hours.

The results obtained in typical experiments on the oxidation of xylose in the presence of calcium, magnesium, strontium, and barium carbonate are given in table 1 . In general, the current efficiency is high but occasionally lower current efficiencies are obtained, as in the experiment in which strontium carbonate was used. This lower efficiency is not characteristic of strontium, as subsequent oxidations in the presence of strontium carbonate gave higher efficiencies. Occasionally in the preparation of the calcium, barium, and magnesium salts the efficiency is lower than that cited. The cause of these small variations is not known.

\section{EXPERIMENTAL DETAILS}

\section{OXIDATION METHOD}

A series of electrolytic oxidations of xylose was conducted under like experimental conditions except that different alkaline earth carbonates and bromides were used. In each experiment $112.5 \mathrm{~g}$

4 This work was done prior to the publication of Hockett (J. Am. Chem. Soc. 56, 994 (1934).

5 Isbell. U. S. Patent No. 1964734 (1934).

6 Isbell. NBS J. Research, 14, 305 (1935) RP770. 
of xylose $(0.75$ mole $)$ and 0.06 mole of alkaline earth bromide were added to 0.4 mole of alkaline earth carbonate suspended in $1,500 \mathrm{ml}$ of water and saturated with $\mathrm{CO}_{2}$. The mixture was placed in a 2-liter 3 -necked flask, cooled with running water, and equipped with a mechanical stirrer and two graphite electrodes $2.25 \mathrm{~cm}$ in diameter, which were immersed to a depth of $8.6 \mathrm{~cm}$. A 1-ampere current was employed which required about 15 volts. The anode current density was 1.5 amperes $/ \mathrm{dm}^{2}$. The direction of the current was reversed several times during the oxidation in order to dissolve the deposit which formed on the cathode. At various times, as given in table 1, the amount of unoxidized sugar was determined by analysis, from which the amount of oxidation was calculated. In all cases the predominant product was the alkaline earth salt of xylonic acid. The calcium, magnesium, and strontium salts were separated in the crystalline state.

\section{PREPARATION OF CALCIUM XYLONATE}

The electrolyzed solution obtained as outlined above from the oxidation of $112.5 \mathrm{~g}$ of xylose in the presence of calcium bromide and calcium carbonate was filtered and the filtrate evaporated in vacuo to about $150 \mathrm{ml}$. After seeding with crystalline calcium xylonate considerable crystalline material formed, which was not separated until after adding about $50 \mathrm{ml}$ of methyl alcohol and allowing the solution to stand for several days in order to increase the yield. In this way $110 \mathrm{~g}$ of crystals was obtained. The product after recrystallization from hot water was substantially pure calcium xylonate, $\mathrm{Ca}\left(\mathrm{C}_{5} \mathrm{H}_{9} \mathrm{O}_{6}\right)_{2} \cdot 2 \mathrm{H}_{2} \mathrm{O}$. The mother liquor after evaporation of the alcohol was light-colored and suitable for repeating the process by the addition of xylose and calcium carbonate. At $20^{\circ} \mathrm{C}, 27.7 \mathrm{~g}$ of the salt dissolves in $100 \mathrm{~g}$ of water.

\section{PREPARATION OF MAGNESIUM XYLONATE}

The electrolyzed solution obtained as outlined above from the oxidation of $112.5 \mathrm{~g}$ of xylose in the presence of magnesium bromide and carbonate was filtered and the filtrate evaporated in vacuo to a thick sirup, which crystalized to a nearly solid mass after standing a few days. This material was triturated with methyl alcohol, collected on a filter, and dried. The crude product was then recrystallized from $150 \mathrm{ml}$ of boiling water and air-dried at $30^{\circ} \mathrm{C}$. The resulting product $(122 \mathrm{~g})$ was substantially pure magnesium xylonate, $\mathrm{Mg}\left(\mathrm{C}_{5} \mathrm{H}_{9} \mathrm{O}_{6}\right)_{2} \cdot 3 \mathrm{H}_{2} \mathrm{O}$. The yield was approximately 80 percent. Subsequent preparations have been made in which electrolyte, after concentrating to a sirup and seeding with crystalline magnesium xylonate, yielded satisfactory crops of nearly pure product without the use of alcohol. The product was recrystallized from water and air-dried.

Analysis calculated for $\mathrm{Mg}\left(\mathrm{C}_{5} \mathrm{H}_{9} \mathrm{O}_{6}\right)_{2} .3 \mathrm{H}_{2} \mathrm{O}: \mathrm{MgO}, 9.87 ; \mathrm{H}_{2} \mathrm{O}, 13.24$. Found: $\mathrm{MgO}, 9.85 ; \mathrm{H}_{2} \mathrm{O}, 13.40$. In 6 percent aqueous solution, $[\alpha]_{\mathrm{p}}^{20}=+14.70$. About $30 \mathrm{~g}$ of magnesium xylonate dissolves in $100 \mathrm{~g}$ of water at $20^{\circ} \mathrm{C}$. 


\section{PREPARATION OF STRONTIUM XYLONATE}

The electrolyte obtained by the oxidation of $112.5 \mathrm{~g}$ of xylose in the presence of strontium bromide and carbonate was filtered and the filtrate evaporated in vacuo to about $150 \mathrm{ml}$. Methyl alcohol was added to the solution until it was slightly turbid, and it was seeded with crystalline strontium xylonate. Crystallization began at once. After standing overnight the crystals were collected on a filter, washed with ice water, and air-dried $(114 \mathrm{~g})$. The product was nearly pure strontium xylonate. After one recrystallization from hot water, in 5 percent solution, $[\alpha]_{\mathrm{p}}^{20}=+9.8^{\circ}$.

Analysis calculated for $\mathrm{Sr}\left(\mathrm{C}_{5} \mathrm{H}_{9} \mathrm{O}_{6}\right)_{2} .5 \mathrm{H}_{2} \mathrm{O}: \mathrm{H}_{2} \mathrm{O}, 17.74 ; \mathrm{Sr}, 17.26$. Found: $\mathrm{H}_{2} \mathrm{O}, 17.71 ; \mathrm{Sr}, 17.32$. This product appears to be the same as that reported by Kiliani; ${ }^{7}$ it appears to differ in the amount of water of crystallization from the product reported by Allen and Tollens. $^{8}$

WAShington, January 22, 1935.

7 Kiliani. Ber. Deut. Chem. Ges. 59, 2462 (1926).

8 Iiebigs Ann. Chem. 260, 306 (1890). 